- York who leads one of these consortia, says that the programme sped up the development of technologies such as robotic crystallization systems and automated high-throughput structure screening. He adds that all structural biology benefits from these advances, as well as from the thousands of solved protein structures that have been deposited in the PSI's Structural Biology Knowledgebase (Nature Publishing Group partners with the NIGMS to maintain this database).

But many of the structures produced by the PSI, which were based on theoretical models, turned out to be irrelevant to biological functions, counters Gregory Petsko, a crystallographer at Brandeis University in Waltham, Massachusetts. If the PSI's budget had instead funded a few hundred individual investigators, each competing to work on specific structures, they probably would have come up with more relevant proteins, he says. He is thrilled that the programme is shutting down. "Put a stake through its heart, bury it in a coffin filled with its native soil - do whatever you can do to keep it from rising again," he says.

Partly in response to such criticisms, the PSI changed its direction in 2010, starting a new phase: PSI:Biology, which directed four centres to work on structures that biologists believe to be particularly important. Almo's group, for instance, is now investigating proteins involved in the immune system, to look for molecules that could be useful as drugs or drug targets. He is disappointed that the PSI is shutting down just as the new phase is becoming productive. "We have a unique resource and we're in the position to start applying this in a powerful way," he says.

But Stefano Bertuzzi, executive director of the American Society for Cell Biology in Bethesda, says that the NIGMS has made the right decision. He thinks that it is better to make strategic cuts that eliminate entire programmes than to trim all projects and debilitate everyone.

That approach also suits Story Landis, director of the National Institute of Neurological Disorders and Stroke (NINDS) in Bethesda, which has already instigated such changes.

\section{"Put a stake through its heart, bury it in a coffin filled with its native soil."} could guarantee funding for only the top $9 \%$ of grant applications it received. So, Landis says, the institute began taking a close look at big, long-running legacy projects that had begun around 2000, and ended about 15 that were unproductive or outdated. This has saved the institute some $\$ 30$ million in the past four years. Ending ineffective clinical trials saved another $\$ 92$ million. NINDS now guarantees funding for $14 \%$ of grant applications.

"The issue wasn't big science, it's more making sure that we manage our dollars effectively," says Landis. Indeed, NINDS will not be abandoning big projects any time soon: the controversial BRAIN Initiative, which aims to develop technologies to map neural circuits, could draw \$40 million in NIH money in 2014 - much of it from NINDS.

Still, a tight budget does seem to be enforcing higher standards among big projects being started across the NIH (see D. Sarewitz Nature $\mathbf{5 0 2}, \mathbf{5 9 5}$; 2013). That is as it should be, says former NIGMS director Jeremy Berg, now director of the Institute of Personalized Medicine at the University of Pittsburgh in Pennsylvania. Berg does not believe that more money necessarily produces better science: in 2010, he performed an analysis which found that middle-sized labs with moderate funding are the most productive (see Nature 468, 356-357; 2010).

Yet Berg does not want big science to disappear. There will always be problems that can be solved only by large initiatives, he says - such projects just have to have clear and relevant goals. "My strong feeling is that the NIH's goal is to try to facilitate the NIH mission, which is improving the nation's health," he says. "It's not a jobs programme for scientists."

Lorsch says that more changes can be expected at the NIGMS in the coming year, but he stresses that it will not be a battle between big science and little labs. "People set up a dichotomy of investigator-initiated projects versus team science, but that's not the contrast we're making," he says. And there could be room for growth in a medium-sized category. Lorsch says that the NIGMS is looking at new funding mechanisms, such as grants with multiple principal investigators and 'supergroups' composed of scientists from different fields. .

\title{
Warsaw talks to thrash out UN climate roadmap
}

\section{Costs of reducing emissions may be flashpoints in path towards 2015 Paris treaty.}

\section{BY JEFF TOLLEFSON}

A $\mathrm{t}$ a major United Nations climate summit in Warsaw this week, a plan is being hammered out for negotiations on a new climate treaty to be finalized in Paris in two years' time. Delegates from 195 nations are also seeking to obtain commitments from countries to limit their greenhouse-gas emissions between now and 2020. But the path forward is rife with disputes between rich and poor countries over funding, and how to allocate and enforce emissions reductions.

The conference aims to outline the schedule and to set parameters for negotiations ahead of the next major climate summit in Paris in 2015, when countries hope to forge a treaty to follow the 2009 agreement settled on in Copenhagen.

At that meeting, negotiations over a formal treaty broke down, but eventually resulted in a set of non-binding pledges - the Copenhagen Accord - for emissions reductions until 2020. The accord also blurred the distinction between developed countries, which were bound by the 1997 Kyoto Protocol to reduce emissions, and developing countries, which had no such obligations. Since then, negotiators have worked on how to structure a new framework that would involve climate commitments from all countries - including China, now the world's largest emitter, and the United States, which never ratified the Kyoto Protocol (E. Diringer Nature 501, 307-309; 2013).

The Warsaw talks are split into two main tracks. One focuses on the architecture of a new global climate treaty that would take effect after 2020, when the current Copenhagen commitments expire. The second examines what can be done to strengthen commitments between now and 2020 to increase the chance of limiting global warming to a target of $2{ }^{\circ} \mathrm{C}$ above pre-industrial temperatures (see 'Emissions up in the air?').

The European Union (EU), for example, has proposed a multi-stage process, whereby commitments for climate action post- 2020 would be registered next year and then subjected to an international assessment to determine how well the commitments measure up against each other and against scientific assessments. The final commitments would 
w then be registered in Paris in 2015. By getting countries to volunteer their climate commitments and comparing them in this way, the hope is that nations with unambitious targets might be shamed into strengthening them. The EU has also called for a review of pre-2020 commitments.

Tasneem Essop, who is tracking negotiations for the environmental group WWF in Cape Town, South Africa, says that these shortterm commitments are crucial for pointing the world in the right direction. "The biggest challenge will be to ensure that emissions do peak within this decade," she says.

The cost of reducing emissions could be the first flashpoint in Warsaw. In Copenhagen, developed countries agreed to provide US $\$ 30$ billion in climate aid from 2010 to 2012, and to increase climate support to developing countries to $\$ 100$ billion annually by 2020 . Although the short-term commitments were largely met, there is no clear plan for attaining the goal of $\$ 100$ billion a year. From emerging giants such as Brazil and China to poor countries in Africa, developing nations are demanding that wealthy countries ramp up funding and create a viable path to this goal.

With public coffers strapped, many developed nations are looking for other funding sources. One possibility is to place some type of levy on international aviation, which is being considered by the International Civil Aviation Organization in Quebec, Canada. The body has committed to craft an agreement by 2016 that could take effect by 2020 .

Negotiators in Warsaw will haggle over how to finance and ultimately deploy climate aid through organizations such as the newly launched Green Climate Fund, based in Incheon, South Korea. Another flashpoint is the developing countries' demand for a 'loss and damage' mechanism to compensate poor countries irreparably harmed by climate change.

But the biggest questions will centre on the framework for the treaty in 2015. Before Copenhagen, the emphasis was on a treaty similar to the Kyoto Protocol that would lock in legally binding emissions reductions. In Copenhagen, the United States and other developed countries pushed for an alternative that would allow individual countries to register commitments, which would then be reviewed at an international level. Delia Villagrasa, a senior adviser for the European Climate Foundation in Brussels, says that the talks are moving towards this bottom-up approach, which would be combined with a formal review to assess commitments and identify ways to scale them up. The world could get its first hint of what such a system might look like as the talks wrap up next week.

"Warsaw will bring some clarification on the structure of the new agreement," Villagrasa says. "That's not sexy for the media, but it's important."

\section{EMISSIONS UP IN THE AIR?}

Countries will discuss how to reduce greenhouse-gas emissions at this week's climate summit in Warsaw. Current commitments expire in 2020 and fall short of climate goals.

After rising by about 3\% annually in the past decade, global emissions of carbon dioxide increased by just $1.1 \%$ in 2012 .

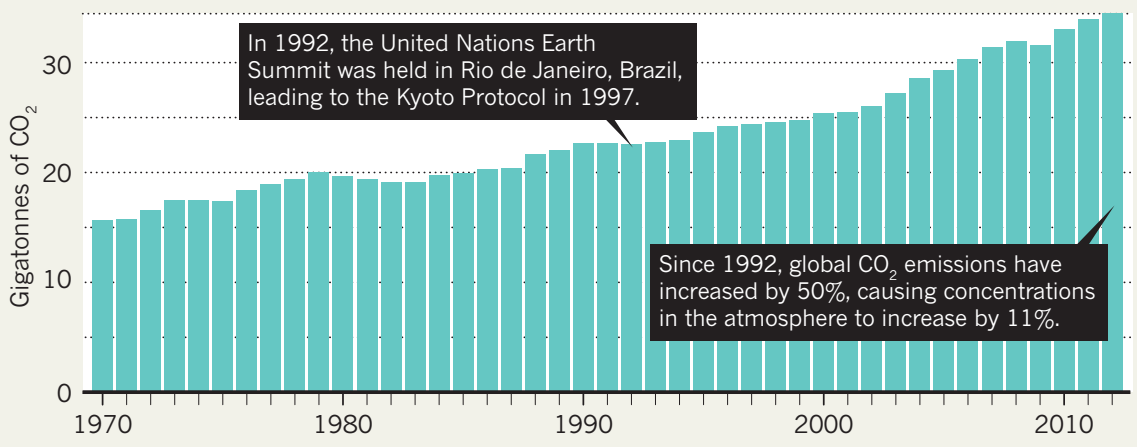

Developing countries, led by China, now emit more greenhouse gases than developed countries, although their per-capita emissions are much lower.

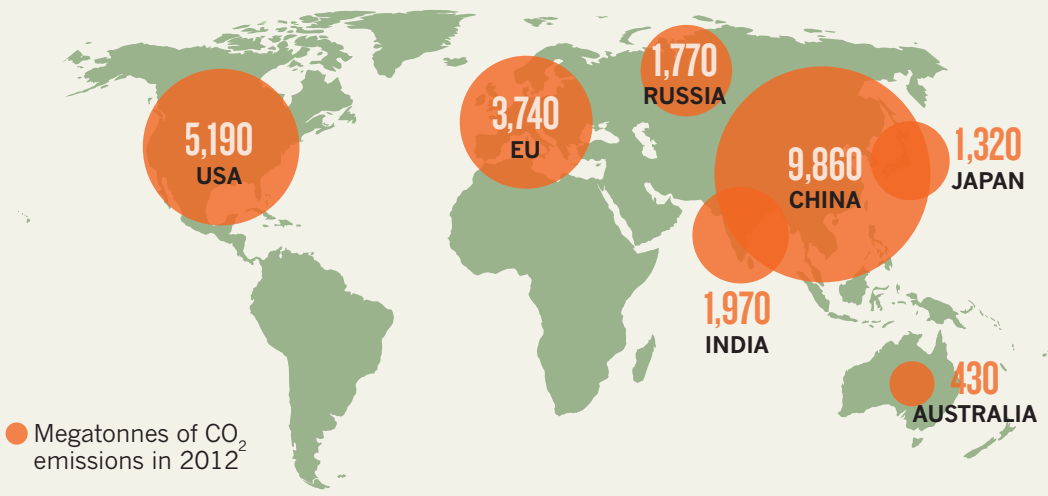

Various trajectories for global emissions are depicted according to their resulting temperature rises by 2100 . Current commitments to reduce emissions by 2020 are not sufficient to limit warming to $2{ }^{\circ} \mathrm{C}$.

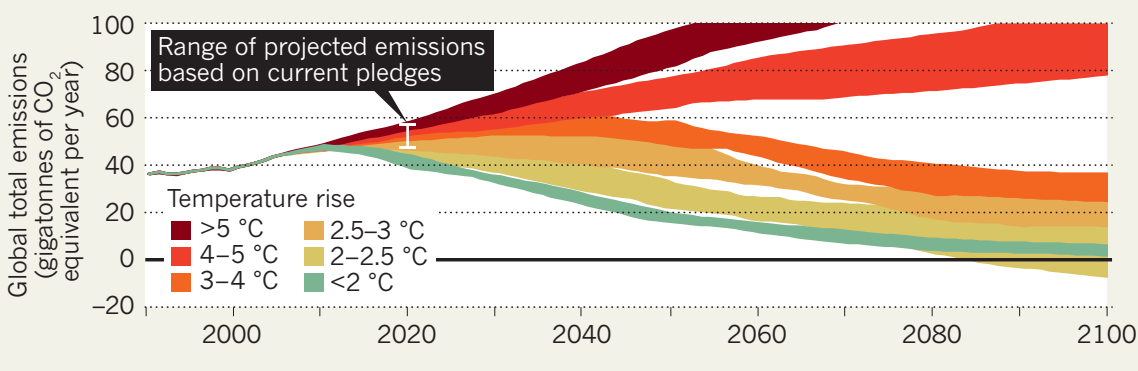

Global climate investments by governments, businesses and consumers topped an estimated US $\$ 359$ billion in 2012. Some $\$ 39$ billion to $\$ 62$ billion, including $\$ 4$ billion to $\$ 11$ billion in government aid, moved from wealthy to poor countries.

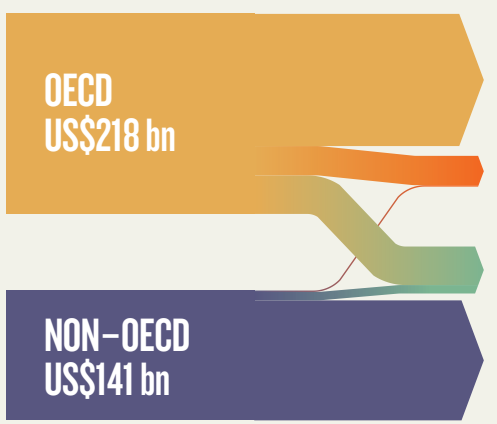

$100 /$ of all climate finance spent by countries in the Organisation for Economic Co-operation and Development (OECD) entirely within their own borders.

$00 /$ flows to OECD countries from international Y\% sources, largely from other developed nations.

$150 /$ flows to non-OECD countries from international $3 \%$ sources; OECD-to-non-OECD flows comprise $12 \%$ of all climate finance.

260/ of climate finance spent by non-OECD countries $30 \%$ entirely within their own borders. 